\title{
Fontes de informação na Web: apropriação, uso \\ e disseminação da informação étnico-racial no movimento negro da Paraíba
}

\author{
Sources of information on the Web: Ownership, use \\ and dissemination of racial and ethnic information \\ in the Afro-Brazilian movement from the \\ state of Paraíba, Brazil
}

Leyde Klebia Rodrigues da SILVA'

Mirian de Albuquerque $\mathrm{AQUINO}^{2}$

\section{Resumo}

O artigo analisa como o Movimento Negro do Estado da Paraíba faz a apropriação das fontes de informação na Web e usa-as na perspectiva de disseminação da informação étnico-racial. As fontes de informação podem ser utilizadas como um canal de disseminação da informação étnico-racial para auxiliar os grupos sociais e etnicamente invisibilizados na atual sociedade da informação-conhecimento-aprendizagem-comunicação, em cujo local o preconceito, a discriminação e o racismo fazem parte do cotidiano dos sujeitos. O universo da pesquisa foi o Movimento Negro Organizado da Paraíba, e os participantes foram quatro ativistas desse movimento: o Núcleo de Estudantes Negras e Negros da Universidade Federal da Paraíba e a Organização de Mulheres Negras na Paraíba. Os resultados mostraram que a ferramenta mais utilizada para veicular a informação é o e-mail. Conclui-se que a apropriação das fontes de informação já utilizadas deve servir como um espaço virtual de armazenamento da informação produzida.

Palavras-chave: Disseminação da informação. Fontes de informação na Web. Informação étnico-racial. Movimento Negro da Paraíba. Uso da informação.

\begin{abstract}
This article analyzes how the Afro-Brazilian Movement from the state of Paraiba uses information sources from the Web with the purpose of disseminating racial and ethnic information. The information sources can be used as a channel for the dissemination of racial and ethnic information to assist the socially and ethnically invisible groups in the current information-knowledge-learning-communication society, in which prejudice, discrimination and racism are part of the subjects' daily life. The research involved the Afro-Brazilian Movement from the State of Paraíba. The participants were four activists from the following groups: Center for Afro-Brazilian/women Students and Afro-Brazilian/men Students from the Federal University of Paraíba, Organization of Afro-Brazilian Women from the state of Paraíba. The results showed that the most common tool for disseminating information was via e-mail. We conclude that by using the information sources, the Afro-Brazilian Movement/blog will serve as a virtual space for storing the information collected.
\end{abstract}

Keywords: Information dissemination. Information sources from the Web. Racial and ethnic information. Afro-Brazilian Movement from the State of Paraíba. Information use.

\footnotetext{
1 Universidade Federal da Paraíba, Centro de Ciências Sociais Aplicadas, Programa de Pós-Graduação em Ciência da Informação. João Pessoa, PB, Brasil.

2 Universidade Federal da Paraíba, Centro de Ciências Sociais Aplicadas, Departamento de Ciência da Informação. Cidade Universitária, Campus I, 58095-230, João Pessoa, PB, Brasil. Correspondência para/Correspondence to: M.A. AQUINO. E-mail:<miriabu@gmail.com>.

Recebido em 7/12/2012, reapresentado em 10/12/2013 e aceito para publicação em 19/2/2014.
} 


\section{Introdução}

A compreensão sobre a necessidade da disseminação da informação que aborda as questões étnico-raciais nas universidades pouco ajudou para se perceber a sólida contribuição de negros na formação da sociedade brasileira. O evento da pós-abolição mergulhou o povo negro na pobreza e no abandono, sem chances de acesso à informação e à educação. O déficit histórico do escravismo não foi totalmente reconhecido e reparado pelos diversos setores do nosso país, porque permanece ainda o discurso da cordialidade e das relações harmoniosas, defendido pela ideologia da democracia racial, colaborando para a invisibilidade de negros na sociedade da informação-conhecimento-aprendizagem-comunicação.

Na ciência, os africanos e os afrodescendentes foram estudados como objetos, sem serem considerados sujeitos capazes de produzir informação e gerar conhecimento sobre sua história e cultura. Os estudos e as pesquisas ainda não reconheceram totalmente que a apropriação dos saberes não é privilégio apenas de um grupo dominante que continua detendo o poder na atual sociedade, ignorando que os saberes pertencem à humanidade. Na literatura das áreas de Biblioteconomia/ Ciência da Informação pouco se discute sobre a importância, o valor e o uso da informação de interesse de grupos específicos (negros, indígenas, deficientes, homossexuais, mulheres, dentre outros). Em geral, nessas áreas, aborda-se a informação para o público como um todo, mas raramente especificam-se os grupos a que se destina essa informação. Em razão disso, é necessário que seus pesquisadores se preocupem com a produção e disseminação dessa informação na atualidade, momento em que a cultura digital agrega, de forma sutil ou velada, determinados estereótipos referentes a grupos específicos historicamente discriminados pela cor e pobreza.

Portanto, este artigo discute o uso e a apropriação das ferramentas da Web na perspectiva da disseminação da informação étnico-racial e da memória do Movimento Negro Organizado da Paraíba (MNOPB), partindo do princípio de que as Ciências Sociais Aplicadas precisam exercitar práticas de pesquisas que possam evidenciar a invisibilidade de negros nas instituições públicas da sociedade brasileira.

\section{Fontes de informação: passado e presente}

A história da humanidade sempre sobreviveu na dependência das fontes de informação. Elas foram transformando-se, renovando-se, reatualizando-se, adquirindo novas formas e moldando-se em novos espaços. Também são responsáveis por carregar e armazenar a informação que age como formadora e transformadora de opiniões. Por fonte de informação, entende-se qualquer recurso que responda a uma demanda de informação por parte de usuários-aprendentes ${ }^{3}$ e que gere ou veicule informação, influenciando na geração do conhecimento e do aprendizado. Essas fontes incluem produtos e serviços de informação, pessoas ou rede de pessoas, programas de computador etc.

Vive-se hoje numa sociedade da informação-conhecimento-aprendizagem-comunicação cujas fontes de informação foram afetadas por momentos significativos do progresso da ciência e da técnica bem como a revolução das tecnologias intelectuais impactou o mundo com seu volume incontornável de informação que se tornou objeto de consumo, mercadoria. A discussão sobre uma sociedade da informação já vem sendo introduzida no contexto mundial desde a década de 1960 com Peter Drucker que, em 1966, no bestseller "The Age of Discontinuity", se reporta a uma sociedade pós-industrial. Nesse contexto, alguns autores vão anunciar e fundamentar o aparecimento de uma nova sociedade denominada "A Sociedade da Informação". Nela, conhecimento, aprendizagem e comunicação são elementos fundamentais que têm a potencialidade de estabelecer conexões entre si e de se interconectar a ponto dos seus habitantes desenvolverem competências e habilidades que possibilitem o exercício da criatividade, pautados pelos seus anseios e necessidades, reforçadas pelos desafios impostos pela cultura digital.

A informação é "Um instrumento modificador da consciência do indivíduo e de seu grupo social [que produz conhecimento e] modifica o estoque mental de

\footnotetext{
3 O termo "aprendente"surgiu nos anos 1980 e 1990 na esteira das teorias gerenciais e referia-se ao contexto complexo das inter-relações humanas, incluindo as que ocorrem entre seres humanos e máquinas inteligentes, em empresas tecnicamente sofisticadas (Assmann, 1998).
} 
saber do indivíduo e traz benefícios para seu desenvolvimento e para o bem-estar da sociedade em que ele vive" (Barreto, 2002, p.49). Essa "Informação deve ser ordenada, estruturada ou contida de alguma forma, senão permanecerá amorfa e inutilizável [...] para nós de alguma forma, e transmitida por algum tipo de canal" (McGarry, 1999, p.11).

Alguns autores afirmam que ter mais informação é ter mais conhecimento e ter conhecimento é ter poder, que pode ser exercido sobre o outro. Na visão de Burke (2003), alguns sociólogos defendem a tese de que estamos numa "Sociedade do Conhecimento", devido à expansão de ocupações que produzem e disseminam o conhecimento, mas precisamos considerar que nem sempre as pessoas têm acesso a ele. O autor afirma que o conhecimento é também uma questão política que está "Centrada no caráter público ou privado de informação, e de sua natureza mercantil e social [e que] a mercantilização da informação é tão velha quanto o capitalismo"(Burke, 2003, p.11). O conhecimento só existe se houver uma fonte de informação que forneça subsídios para a construção do conhecimento.

Há aqueles que defendem a "sociedade da aprendizagem" (Assmann, 1998) porque somos pressionados cotidianamente a aprender e a reaprender, a usar as ferramentas digitais como "Um processo fundante para vida inteira" (Aquino, 2005). Todas as pessoas são convocadas para aprender e transmitir, cada vez mais, saberes evolutivos e adaptados (Delors, 1999) ao novo contexto. Viver o contexto em que eclodem as tecnologias intelectuais é estar constantemente em "estado de aprendência" (Fernandez, 2001). Isso significa que "[...] a sociedade inteira deve entrar em estado de aprendizagem e transformar-se numa imensa rede de ecologias cognitivas" (Assmann, 1998, p.19). E o sujeito aprendente é "Aquela articulação que vai armando o sujeito cognoscente e o sujeito desejante sobre o organismo herdado, construindo um corpo sempre em intersecção com outro (conhecimento-cultura [...]) e com outros (pais, professores, meios de comunicação)" (Fernández, 2001, p.55).

Essa nova sociedade caracteriza-se também como uma sociedade da comunicação porque as "Tecnologias contemporâneas estabelecem uma dinâmica própria de comunicação mediada por linguagens, em que estas linguagens possibilitam a construção de representações ou expressões simbólicas específicas, dando condições ao surgimento de novas práticas dentro dos processos representativos" (Gomes, 2007, online). Além disso, estamos vivendo "a diversidade que emerge na globalização contemporânea [e] traz elementos novos para o pensamento" com a "movimentação de grupos sociais que trafegam política e educacionalmente no espaço dos direitos civis e humanos"(Sodré, 2013, online).

As tecnologias intelectuais potencializaram o surgimento rápido e mutável de fontes de informação, sobretudo no que se refere à rede Web (Sales \& Almeida, 2007). Os modelos ou parâmetros adotados pelas fontes de informação disponíveis vêm sendo modificados, ampliados e diversificados, tornando-se cada vez mais "Eficientes, rápidas e abrangentes, vencendo barreiras geográficas, hierárquicas e financeiras" (Campello et al., 2000, p.23).

Em sua análise sobre a relação tecnologia e profissionais, autores como Tomaél et al. (2000, p.5) afirmam que "Nenhuma tecnologia da informação teve impacto tão forte nos profissionais da informação como a Internet".

Dentre as inúmeras fontes de informação da Web, é possível destacar pelo menos nove mais conhecidas e utilizadas:

- Sites e websites: são um conjunto de páginas Web ou hipertextos acessíveis; pelo protocolo de transferência da Internet;

- Portais: um tipo de site que congrega conteúdos de diversos tipos (áudio, vídeo, imagem, texto etc.);

- Blogs: espécie de diário Web que apresenta características como a personalização. Podem ser desenvolvidos para serem utilizados individual ou coletivamente;

- Microblogs: considerados ferramentas de blogs em formato mais simples e servem para postagens com limitações de tamanho;

- Youtube: permite que os usuários-aprendentes carreguem e compartilhem vídeos em formato digital;

- Redes sociais (Orkut, Facebook, Ning, Linkedin, entre outras): são uma forma de representar as relações humanas. O crescimento das redes sociais perpassa as relações pessoais e atinge também os âmbitos organizacional, social, político e científico; 
- Grupos de Discussão ou Comunidades Virtuais: rede eletrônica de comunicação interativa autodefinida, organizada em torno de um interesse ou finalidade compartilhada;

- Buscadores e Metabuscadores: são motores de busca, programas feitos para auxiliar a busca de informação armazenada na rede mundial (www) ou a Internet.

O potencial de aplicação das ferramentas de busca online é necessário no contexto dinâmico da sociedade da informação-conhecimento-aprendizagem-comunicação, tendo como função orientar o usuário-aprendente à fonte desejada.

\section{Apropriação, uso e disseminação das fontes de informação}

Na visão de Chartier (1999, p.77), "Apropriar-se é transformar o que se recebe em algo próprio, é produzir um ato de diferenciação que se contrapõe a qualquer tentativa rígida imposta [...], é atividade de invenção, produção de significados". Sobre essa questão, Perrotti e Pierrucini (2007, p.27) recuperam a noção de apropriação de Perla Serfaty-Garzon:

[...] veicula duas ideias dominantes. De uma parte a de adaptação de alguma coisa a um uso definido ou a uma destinação precisa; de outra, decorrente da primeira, a de ação visando a tornar alguma coisa sua. Nesse sentido, a apropriação não é possível senão em relação a qualquer coisa que pode ser atribuída e, enquanto tal pode, ao mesmo tempo, servir de suporte à intervenção humana e ser possuída. Todavia, a propriedade aqui é [também] de ordem moral, psicológica, afetiva [...]. A apropriação é, desse modo, ao mesmo tempo, uma tomada do objeto e uma dinâmica de ação sobre o mundo material e social com uma intenção de construção do sujeito.

A noção de apropriação utilizada como instrumento de conhecimento pode também reintroduzir uma nova ilusão e pressupor a compreensão da cultura. Para Chartier (1999), o conceito de cultura não é apenas um domínio particular de produções e de práticas supostamente distinto de outros níveis, como o econômico e o social. Segundo o autor, a cultura também faz parte dessas esferas, pois "[...] não existe prática que não se articule sobre as representações pelas quais os indivíduos constroem o sentido de sua existência" (Chartier, 1999, p.18). Ele afirma que a cultura apresenta dois aspectos: 1) os mecanismos da dominação simbólica, cujo objetivo é tornar aceitável, pelos próprios dominados, as representações e os modos de consumo que, precisamente, qualificam (ou antes, desqualificam) sua cultura como inferior e ilegítima e; 2) as lógicas específicas em funcionamento nos usos e nos modos de se apropriar do que é imposto.

A apropriação remete-se à forma como lemos, interpretamos e compreendemos as fontes de informação nas fontes orais, escritas e digitais para produzir conhecimento. O uso das fontes de informação ocorre a partir do momento em que o usuário-aprendente toma para si a informação, lê, interpreta. Ele é capaz de atribuir sentidos, gerar conhecimento e modificar as estruturas do pensamento. É uma "Necessidade de uma reforma do pensamento, portanto, de uma reforma do ensino" (Morin, 2004, p.9), de saberes. Para este autor, "A reforma do pensamento é que permitiria o pleno emprego da inteligência para responder a esses desafios e permitiria a ligação de duas culturas dissociadas [...]. A reforma do ensino deve levar à reforma do pensamento, e a reforma do pensamento deve levar à reforma do ensino" (Morin, 2004, p.20).

Em relação ao uso das fontes de informação na Web, que é um dos pontos-chave deste estudo, alguns autores estabelecem considerações sobre os espaços de informação e dos usuários-aprendentes:

A tecnologia [...] objetiva possibilitar o maior e melhor acesso à informação disponível, e o critério da Ciência da Informação, que intervém para qualificar este acesso em termos das competências que o receptor da informação deve ter para assimilar a informação, ou seja, para elaborar a informação para seu uso, seu desenvolvimento pessoal e dos seus espaços de convivência. Não é suficiente que a mensagem esteja disponível, ela deve também poder ser apropriada pelo receptor (Smit \& Barreto, 2002, p.15, grifo nosso).

Com base nesse argumento, reafirma-se a importância da apropriação das fontes de informação pelo usuário-aprendente. Elas não podem ser apenas utilizadas já que a cultura, hoje, passa não exclusivamente pelo conhecimento teórico-prático, mas também pelo uso de 
novos instrumentos de produção e pela comunicação entre os homens. A disseminação da informação por meio do uso da Internet pode contribuir para uma sociedade mais informada, mas não garante isso. Além do acesso às tecnologias intelectuais, a população necessita de acesso à educação para fins de utilização de maneira competente.

É a educação o elemento-chave para a construção de uma sociedade da informação e condição essencial para que pessoas e organizações estejam aptas a lidar com o novo, a criar e, assim, a garantir seu espaço de liberdade e autonomia. A dinâmica da sociedade da informação requer educação continuada ao longo da vida, que permita ao indivíduo não apenas acompanhar as mudanças tecnológicas, mas, sobretudo, inovar. No Brasil, até mesmo a educação básica ainda apresenta deficiências marcantes. Particularmente nos segmentos sociais de baixa renda e em regiões menos favorecidas, o analfabetismo permanece como realidade nacional. O desafio, portanto, é duplo: superar antigas deficiências e criar as competências requeridas pela nova economia (Takahashi, 2000, p.7).

Portanto, o uso efetivo dos estoques informacionais só será possível se os indivíduos tiverem competência para assimilar essa informação e a educação ganhe "Maior eficiência e alcance cada vez maior número de comunidade e regiões" (Takahashi, 2000, p.7), guetos e favelas, onde a maioria da população negra habita. Concorda-se com Bastos (2005, p.20), ao afirmar que:

[...] apesar de toda evolução do acesso à informação, proporcionado pelas tecnologias de informação e comunicação, continua sendo primordial um estudo sobre as necessidades de informação do indivíduo na sociedade, pois a maioria não possui repertório suficiente e adequado para receptar e processar o excesso de informações, e atuar como cidadãos na sociedade.

A disseminação da informação, segundo Bastos (2005), deve ir além da socialização do conhecimento, chegar até à produção de conhecimento com base na informação acumulada. Ao assumir novos papéis (interatividade, agilidade, diminuição de espaço na armazenagem de informação) frente às fontes tradicionais que armazenam e disseminam a informação. As fontes de informação da Web podem se tornar um espaço onde o usuário-aprendente também deve explorar as possibilidades de armazenar e preservar a informação, tanto do meio físico para o virtual (digitalização), quanto pensar e criar estratégias e mecanismos para a preservação da informação existente apenas no meio virtual.

\section{Métodos}

A abordagem qualitativa tende a responder às questões particulares nas Ciências Sociais Aplicadas e dar um novo sentido aos problemas específicos e compreensão dos significados. Trata-se de uma abordagem que nos incita "A repensar o estudo das necessidades socioculturais dos meios de vida" (Groulx, 2008, p.98) e permite ressaltar "A natureza socialmente construída da realidade, a íntima relação entre o pesquisador e o que é estudado e as limitações situacionais que influenciam a investigação" (Denzin \& Lincoln, 2006, p.23). Esses autores entendem que pesquisadores qualitativos buscam soluções para tentar resolver as questões que apontam o modo como a experiência social é criada e adquire significados.

O universo de pesquisa é o Movimento Negro Organizado da Paraíba (MNOPB), formado por um conjunto de diversas organizações negras, a saber: a) comunidades descendentes de antigos Quilombos (Caiana dos Crioulos, Zumbi etc.); b) grupos artísticos (Banda Ylê Odara, Bateria Show da Escola de Samba Malandros do Morro, Grupo de danças Afroprimitivas, Grupos de Hip-hop); c) grupos de formação (alfabetização, reflexão, professores, intelectuais negros e outros); d) grupos de arte marcial (Badauê dos Palmares, Afronagô e outros); e) entidades de articulação e luta em defesa dos direitos da etnia negra (Movimento da Ação Negra e Agentes de Pastoral Negros); f) grupos de gênero (Mulheres Negras, Bamidelê; g) comunidade de Religião dos Orixás (terreiros); dentre outras formas de organização (Movimento Negro da Paraíba, 2007). Escolheu-se o MNOPB por entender que os grupos ativistas desse movimento se posicionam como porta-vozes de afrodescendentes para conseguir valorizar a identidade de seus integrantes, construir sentidos e manifestar seu pertencimento.

Os participantes dessa pesquisa são quatro ativistas negros, vinculados ao Núcleo de Estudantes Negras 
e Negros da Universidade Federal da Paraíba - NENN/ UFPB e à Organização de Mulheres Negras na Paraíba Bamidelê. Na escolha desses sujeitos, foram selecionados, principalmente, os líderes dessas organizações, por supor que estariam mais familiarizados e atualizados acerca dos processos de uso e apropriação das fontes de informação na Web, tendo como finalidade de apropriação, produção e disseminação da informação étnico-racial.

Para saber como os participantes da pesquisa se apropriam das fontes de informação na Web e delas fazem uso, adotou-se a entrevista semiestruturada como instrumento de coleta de dados em que o sujeito tem uma participação ativa e o pesquisador pode fazer perguntas adicionais para esclarecer questões que visem compreender bem mais o contexto.

A transcrição das entrevistas foi feita com base na Análise da Conversação (Marcuschi, 1986) após o término de cada uma, visando a facilitar a identificação dos diálogos, a compreensão do conteúdo e a seleção das partes mais relevantes para a composição da análise.

\section{Discurso do sujeito coletivo: um modo de ler discursos de ativistas do MNOPB}

Para analisar como o MNOPB faz a apropriação, utilização e disseminação das fontes de informação na Web, recorreu-se ao Discurso do Sujeito Coletivo (DSC) que pressupõe um conjunto de princípios e conceitos operacionais, emprestado pela Semiótica de Pierce e pela Teoria das Representações Sociais, representadas por Jodelet (2001) e Moscovici (2003). Eles consideram os fenômenos sociais como "A fonte principal da produção de discursos e estes são assimilados como um fragmento do pensamento social" (Almeida, 2005, p.61). As realidades, segundo Moscovici (2003), são medidas pelas representações, e "[...] uma de suas funções principais é de dar significados de aspectos dessa realidade"(Almeida, 2005, p.71). Essa teoria orienta as ações das pessoas, ligando "sujeito e objeto do conhecimento".

Essa técnica propõe três conceitos operacionais básicos para análise dos discursos dos sujeitos coletivos, a saber: as Expressões-Chave, a Ideia Central e a Ancoragem. As Expressões-Chave são fragmentos extraídos da transcrição literal do discurso do sujeito na entrevista.
A Ideia Central é "A descrição, precisa e direta, dos significados do conjunto dos discursos que foram analisados e destacados nas expressões-chave [...] descreve o sentido de cada um dos discursos analisados e de cada conjunto homogêneo" (Almeida, 2005, p.71). E a Ancoragem é a "Figura metodológica que indica a teoria, o pressuposto, a corrente de pensamento e o fundo do conhecimento que o sujeito aceita e compartilha de uma maneira natural para representar um dado fenômeno da realidade" (Almeida, 2005, p.71).

Nesta análise, o sujeito coletivo é a voz dos ativistas do Movimento Negro do Estado da Paraíba, que se manifesta na primeira pessoa do singular. $O$ entrevistado (sujeito individual) é aquele que fala em nome do grupo (sujeito coletivo) ao qual pertence. O resultado das suposições bem como as considerações e análises representam o sujeito individual e o sujeito coletivo, entendidos como"Um ser ou entidade empírica coletiva, opinante na forma de um sujeito de discurso emitido na primeira pessoa do singular" (Lefèvre \& Lefèvre, 2006, p.518).

O primeiro passo da análise consistiu na leitura dos discursos de cada um dos sujeitos individuais. Em seguida, foram recortados os discursos observando os conceitos operacionais e legendamos (Sujeito A, Sujeito B, Sujeito C e Sujeito D). O segundo passo consistiu em destacar, em negrito, as expressões-chave presentes nas ideias centrais. No terceiro passo, as ideias centrais foram identificadas e redigidas. No quarto passo, foram estabelecidas as categorias do DSC a partir das ideias centrais. Finalmente, o quinto passo consistiu no agrupamento das categorias, formadas a partir de fragmentos dos discursos dos sujeitos, com a finalidade de construir o DSC de cada um dos discursos.

A primeira interlocução com os sujeitos individuais teve como finalidade identificar se o Movimento Negro de João Pessoa utilizava alguma fonte de informação da Web. Caso utilizasse, como se dava o processo de apropriação. Após essa identificação das Ideias Centrais, foram retiradas as Expressões-Chave e delas extraíram-se as categorias "uso de blog e e-mail" e "apropriar para divulgar, disseminar", referentes ao uso e processo de apropriação das fontes de informação na Web. Dessa operacionalização, obteve-se o DSC: 
[...] o próprio movimento negro organizado da Paraíba tem um blog, tem um blog e tem um email, então faz sim [...]. Mas, é um grupo de discussão também que assim como o blog não tá funcionando [...] essas coisas assim, usa pra publicar, para divulgar, [...] a gente tem feito o uso dessa ferramenta para se apropriar e para divulgar [...] (DSC1).

Interpretando o DSC com base no discurso dos "sujeitos coletivos", é possível constatar que o blog e o e-mail são as fontes de informação mais empregadas pelo MNOPB na Web. Na maioria das vezes, o processo de apropriação dessas ferramentas tem como finalidade disseminar a informação de interesse do grupo. A apropriação das ferramentas está associada ao uso de postagens acerca das questões levantadas por um grupo de discussão. Essas postagens são coletivas e espontâneas, e a apropriação das ferramentas efetiva-se por meio delas. Nota-se, entretanto, que, em razão da desorganização do MNOPB, as postagens não têm sido atualizadas.

Os discursos mostram que o grupo usa o blog como a ferramenta mais adequada para a de disseminação da informação. Essa ferramenta, segundo eles, serve para noticiar visões de mundo individuais ou de pequenas coletividades sobre temas variados. No campo da Ciência da Informação, o blog é visto como mais um complemento para disseminar a informação e disponibilizar o conhecimento para usuários-aprendentes que navegam na Web.

Hoje, existe um número de empresas consolidadas no mercado que recorrem a essa ferramenta para construir identidades, aumentar sua credibilidade e divulgar seus produtos. Há também indivíduos que usam essas ferramentas no formato de diário e outros, com fins jornalísticos. É uma ferramenta de fácil publicação, não dependendo do conhecimento prévio por parte do usuário-aprendente da linguagem de programação e a maioria delas é gratuita. Por sua vez, o e-mail é a ferramenta de comunicação que mais evoluiu nas últimas décadas e vem se popularizando à medida que as tecnologias intelectuais também se popularizam.

O discurso do sujeito coletivo mostra que MNOPB, mesmo tendo as ferramentas, não atinge seus propósitos de uso, porque elas se encontram desatualizadas, resultando na desis-tência do uso. Esse distanciamento pode ser atribuído à não funcionalidade da própria organização. A apropriação do blog e do grupo de discussão serve para a divulgação e disseminação da informação recuperada pelo MNOPB. Porém, não há uma periodicidade nessa disseminação, perdendo-se, assim, um requisito básico para que a ferramenta seja utilizada constantemente, que é a atualização da informação disponibilizada.

A segunda interlocução com os entrevistados referiu-se ao uso do e-mail como fonte de informação para a apropriação da informação disseminada pelos ativistas do MNOPB e os tipos que utilizam. Nesse sentido, os posicionamentos dos sujeitos individuais e das Ideias Centrais, retiradas do segundo bloco de dados discursivos, serviram para extrair a categoria"e-mail: veículo de apropriação da informação no MNOPB", com vistas à disseminação e à memória do MNOPB, resultando no discurso do sujeito coletivo: "Utilizo sim, a fonte de informação mais eficaz, ainda é o e-mail, não é o e-mail do Grupo, éo e-mail pessoal" (DSC2).

Os discursos dos sujeitos apontam possibilidades que potencializariam o poder de comunicação dessas ferramentas, tendo em vista o uso que Ihes é atribuído, mas não são devidamente empregadas. Eles informaram que as questões de uso restrito dessas ferramentas estão relacionadas a algumas características que estão agregadas ao seu manuseio, tais como a pouca familiaridade com essas ferramentas, a falta de articulação dos ativistas, a ausência de mobilização de pessoas que poderiam orientar os ativistas a usá-las.

Essa inabilidade, no que concerne ao uso das ferramentas pelos ativistas, contrasta com a literatura e as pesquisas, pois tem sido mostrado que as fontes de informação da Web demandam uma praticidade, que é reconhecida como uma das características das ferramentas digitais contemporâneas. A demanda pela usabilidade é tão simples quanto o uso que se faz dela.

No discurso do sujeito coletivo, constatou-se que a apropriação da informação disseminada pelo MNOPB é feita apenas por meio da troca de e-mails pessoais e não entre os ativistas. Essa ferramenta é considerada mais acessível ao grupo e mais fácil de ser operacionalizada. O e-mail é utilizado para disseminar a informação das quais os ativistas do MNOPB se apropriam nas entidades bem como para os ativistas ligados ao movimento, em âmbito local, estadual e federal. 
Ao que parece a apropriação das ferramentas na Web pode muito contribuir para fortalecer o MNOPB, uma vez que esse movimento caracteriza-se como unidade agregadora de interesses comuns, cujo objetivo maior de suas lutas está voltado para a visibilidade de suas ações que visam à reversão dos preconceitos, discriminações e racismos que afetam historicamente o potencial humano e cultural da população negra, relegando negros à exclusão. Entretanto, a desarticulação e os conflitos internos inerentes ao MNOPB interferem nos efeitos positivos que o uso dessas ferramentas poderia trazer.

A voz dos ativistas expressa que o MNOPB está preocupado em veicular informação étnico-racial para fortalecer essa organização. Embora se autoafirmem como "apáticos", os ativistas mantêm-se atualizados e, atualizando-se, no que concerne à informação étnico-racial, continuam disseminando essa informação entre si, instigando as discussões e reflexões, principalmente quando se trata de temas relacionados ao racismo.

À luz das ideias de Correia (1999, p.114), "O acesso/ uso da informação vai possibilitar a mudança de mentalidade dentro do contexto social do movimento negro, pois, conhecendo sua condição social, ele buscará ser reconhecido enquanto indivíduo, sem afastar-se de sua etnicidade e cultura". Com essa atuação, os ativistas do MNOPB fazem com que a informação passe a ser "Um elemento organizador do processo de comunicação e de apoio da elaboração do conhecimento do indivíduo". Isso conduz esse indivíduo a desenvolver um papel social pautado na liberdade de expressão e a expor a sua cultura, sem que se sinta reprimido ou até mesmo discriminado.

Prosseguindo a interlocução com os ativistas entrevistados, perguntou-se se achavam que as fontes de informação na Web facilitavam a disseminação da informação e solicitou-se que justificassem suas respostas. Dos discursos de cada um deles, foi extraída as categorias "agilidade e rapidez" e "diminui as fronteiras", as quais originaram os discursos dos sujeitos coletivos a seguir:

Facilita sim, porque encurta as fronteiras. Tanto ampliam a possibilidade de você se comunicar, quanto elas ampliam a possibilidade de você organizar a comunicação. Acho que é a rapidez. É a agilidade e praticidade. Ela é importante, ela dissemina a informação. Mas aí a gente tem que repassar de outra forma porque a gente não pode entender que a gente vai divulgar uma ação e que todas as pessoas vão ter acesso, e não vão ter acesso. Então, a gente faz essa reflexão, porque no acesso a gente tá atrás da população branca (DSC3).

Eles disseram que no MNOPB a disseminação da informação é agilizada pelas fontes de informação. Nessa questão, os ativistas entrevistados parecem reconhecer a importância dessas fontes, considerando que, por ser a comunicação simultânea, essa produz agilidade e rapidez encurtando, assim, as fronteiras. Concorda-se com a facilidade na disseminação da informação, pois eles atribuíram sentido ao uso dessas ferramentas. A eficácia da disseminação perpassa a mecânica da simultaneidade no recebimento de informação para alcançar resultados no uso que se faz dela.

Na verdade, o DSC explicita que as ferramentas intensificam a capacidade de organizar a informação e repassá-la, mas cabe ao usuário-aprendente apropriar-se dessas características para atingir o propósito que intenciona. Caso esses propósitos inexistam, as possibilidades da democratização informacional podem ser reduzidas.

O uso das ferramentas deve ser perpetuado para a inclusão étnico-racial e a neutralização das ações direcionadas, desse modo, a preconceitos, discriminações e racismos. Essa iniciativa não é responsabilidade dos meios digitais, mas de questionamentos e críticas dos sujeitos. Aqueles que dominam essas fontes são responsáveis por repassar a informação para a população que não tem acesso a ela. Os meios são apenas suportes facilitadores para que esse fim seja alcançado.

Sendo assim, os ativistas do MNOPB, como agentes da informação étnico-racial, devem reafirmar seu compromisso de"conscientizar a raça negra para que seja feita uma releitura dos acontecimentos a partir da compreensão do seu papel na história" (Movimento Negro da Paraíba, 2007), disseminando a informação étnico-racial para desconstruir o discurso que a exclui.

\section{Conclusão}

As pesquisas sobre as relações étnico-raciais e sua relação com a disseminação de fontes de informação na 
Web implicam em construir e juntar os fragmentos da memória coletiva da história da população negra. Elas possibilitam uma concepção de um conhecimento que sirva para reduzir as discriminações, os racismos e os preconceitos que submetem negros a humilhações, excluindo-os dos diversos âmbitos da sociedade. É possível constatar que, desde o processamento, passando pelo tratamento da informação étnico-racial e chegando à sua disseminação e memória, o profissional da informação deve abandonar o preconceito em relação a qualquer suporte informacional, sejam eles físicos, digitais e virtuais, e fazer com que as fontes de informação étnico-racial da Web possam inovar as práticas de mediação na disseminação dessa informação para os diferentes usuários-aprendentes da grande rede.

Os profissionais da informação, conjuntamente com pesquisadores, professores e alunos, devem construir uma rede social sobre as fontes de informação da Web, aliada às práticas culturais desenvolvidas pelos movimentos sociais que sirvam para desvelar a realidade e as contradições. A partir do ponto de vista de um profissional da informação, que se preocupa com o uso e a apropriação da informação disponibilizada na Web pelos grupos socialmente invisibilizados, entendeu-se que caberia ao Estado e aos Conselhos de Educação elaborar políticas de reparações por meio de programas de ações afirmativas e políticas de informação que orientem a sociedade, seus representantes e a comunidade científica para corrigir as desvantagens e a exclusão nessa sociedade excludente e discriminatória, que invisibiliza seus atores sociais, por meio de preconceitos e diferentes formas de negação de sua cultura de origem, impondo uma cultura dominante, que impera, dita normas e valores, exclui e fecha as portas aos menos favorecidos socialmente.

A disseminação da informação étnico-racial, por meio da Web, faz com que os sujeitos tenham condições de modificar suas ações e, consequentemente, passem a ter maior controle e integração com as instituições sociais de forma mais democrática. Neste estudo, encontram-se fontes de informação da Web que servem de instrumentos para as entidades ligadas ao MNOPB e canais de disseminação da informação étnico-racial. Elas visam ao uso e à apropriação da informação étnico-racial para dar possibilidade ao indivíduo de se tornar mais consciente do espaço em que vive e interagir com ele por meio de sua cultura e de seus direitos e deveres. Percebe-se que o MNOPB é uma entidade que utiliza as fontes de informação da Web para se apropriar da informação étnico-racial e preservar a memória histórico-cultural desse grupo.

Essas ferramentas podem contribuir para ajudar os grupos sociais que lutam por direitos, democracia e justiça. É necessário entender também que a tecnologia, por si só, não atende aos propósitos e às demandas da sociedade. Ela somente é relevante se tiver condições de resolver e/ou buscar soluções para atender aos problemas que atingem os grupos sociais etnicamente vulneráveis e todos aqueles que vivem situações de marginalidade na sociedade da informação-conhecimento-aprendizagem-comunicação.

\section{Referências}

Almeida, C.C. Discurso do sujeito coletivo: reconstruindo a fala do social. In: Valentim, M.L.P. (Org.). Métodos qualitativos de pesquisa em ciência da informação. São Paulo: Polis, 2005. Cap.3, p.59-79.

Aquino, M.A. Informação para educação: construindo dispositivos de inclusão a partir do uso de objetos multimídia na sociedade da aprendizagem. João Pessoa: UFPB, 2005. (Projeto Técnico-Científico).

Assmann, H. Reencantar a educação: rumo à sociedade aprendente. Petrópolis: Vozes, 1998.

Barreto, A.A. Transferência da informação para o conhecimento. In: Aquino, M.A. (Org.). O campo da ciência da informação: gênese, conexões e especificidade. João Pessoa: UFPB, 2002. Cap.3, p.49-59.
Bastos, F.M. Organização do conhecimento em bibliotecas digitais de teses e dissertações: análise da aplicabilidade das teorias macroestruturais para categorização de áreas de assunto. 2005. Dissertação (Mestrado em Ciência da Informação) - Faculdade de Filosofia e Ciências, Universidade Estadual Paulista Júlio de Mesquita Filho, Marília, 2005.

Burke, P. Uma história social do conhecimento: de Gutenberg a Diderot. Rio de Janeiro: Jorge Zahar, 2003.

Campello, B.S.; Cendón, B.V.; Kremer, J.M. Fontes de informação para pesquisadores e profissionais. Belo Horizonte: UFMG, 2000.

Chartier, R. A aventura do livro: do leitor ao navegador, conversações com Jean Lebrun. São Paulo: Unesp, 1999.

Correia, T.M.S. Lemba odu: práticas informacionais no contexto do Movimento Negro de João Pessoa-PB. 1999. Dissertação 
(Mestrado em Ciência da Informação) - Universidade Federal da Paraíba, João Pessoa, 1999.

Delors, J. Educação: um tesouro a descobrir, relatório para a Unesco da comissão internacional sobre educação para o século XXI. São Paulo: Cortez, 1999.

Denzin, N.K.; Lincoln, Y.S. Introdução: a disciplina e a prática da pesquisa qualitativa. In: Denzin, N.K.; Lincoln, Y.S. O planejamento da pesquisa qualitativa: teorias e abordagens. Porto Alegre: Artmed, 2006. Cap.1, p.15-47.

Fernández, A. Os idiomas do aprendente: análise das modalidades ensinantes com famílias, escolas e meios de comunicação. Porto Alegre: Artmed, 2001.

Gomes, P.T. A sociedade da comunicação e seus processos constituintes: ciberespaço, comunidades e ontologias. In: Reunião Anual da Anped, 30., 2007, Caxambu. Anais eletrônicos... Caxambu: ANPEd, 2007. p.1-18. Disponível em: <http:// www.anped.org.br/reunioes/30ra/trabalhos/gt16-3323-int.pdf>. Acesso em: 24 ago. 2012.

Groulx, L.H. Contribuição da pesquisa qualitativa à pesquisa social. In: Poupart, J. et al. A pesquisa qualitativa: enfoques epistemológicos e metodológicos. Petrópolis: Vozes, 2008. p.95-124.

Jodelet, D. Representações sociais: um domínio de expansão. In: Jodelet, D. As representações sociais. Rio de Janeiro: UERJ, 2001. p.17-44.

Lefèvre, F.; Lefèvre, A.M.C. O sujeito coletivo que fala. Interface: Comunicação, Saúde, Educação, v.10, n.20, p.517-24, 2006. Disponível em: <http://www.scielo.br>. Acesso em: 20 nov. 2010.

Marcuschi, L.A. Análise da conversação. São Paulo: Ática, 1986.

McGarry, K. O contexto dinâmico da informação: uma análise introdutória. Brasília: Briquet de Lemos, 1999.
Movimento Negro da Paraíba. Nossa história. 2007. Disponível em: <http://valeuzumbivaleu.blogspot.com.br/2007_ 11_01_archive.html>. Acesso em: 10 ago. 2010.

Morin, E. A cabeça bem-feita: repensar a reforma, reformar o pensamento. Rio de Janeiro: Bertrand do Brasil, 2004.

Moscovici, S. Representações sociais: investigações em psicologia social. Petrópolis: Vozes, 2003.

Perrotti, E.; Pierruccini, I. Saberes e fazer na contemporaneidade. In: Lara, M.; Fujino, A.; Noronha, D.P. (Org.). Informação e contemporaneidade: perspectivas. Recife: Néctar, 2007. p.47-96.

Sales, R.; Almeida, P.P. Avaliação de fontes de informação na internet: avaliando o site do NUPILL/UFSC. Revista Digital de Biblioteconomia e Ciência da Informação, v.4, n.2, p.67-87, 2007.

Smit, J.W.; Barreto, A.A. Ciência da Informação: base conceitual para a formação do profissional. In: Valentim, M.L.P. (Org.). Formação do profissional da informação. São Paulo: Polis, 2002. Cap.1, p.9-23.

Sodré, M. Educação para o diverso. In: A Cor da cultura, Rio de Janeiro, 2013 (22 ago). Disponível em: <http://www.acorda cultura.org.br/artigos/22082013/educacao-para-o-diversopor-muniz-sodre>. Acesso em: 10 out. 2013.

Tomaél, M.l. et al. Fontes de informação na internet: acesso e avaliação das disponíveis nos sites de universidades. In: Seminário Nacional de Bibliotecas Universitárias, 11., 2000 Florianópolis. Anais... Florianópolis: UFSC, 2000. Disponível em:<snbu.bvs.br/snbu2000/docs/pt/doc/t138.doc>. Acesso em: 13 set. 2010.

Takahashi, T. (Org.). Sociedade da informação no Brasil: livro verde. Brasília: Ministério da Ciência e Tecnologia, 2000. 
